\title{
The use of histopathology in the practice of necropsy
}

\author{
J O Williams, M J Goddard, G A Gresham, B A Wyatt
}

\begin{abstract}
Aim-To examine current practice and to establish criteria for the use of histopathology in necropsy practice.

Methods-During an audit of necropsy reporting, consensus could not be reached about the use of routine histopathology. Therefore local guidelines were formulated and current practice was compared with these guidelines. Fifteen consecutive necropsies undertaken by each consultant were reviewed and the use of histopathology noted.
\end{abstract}

Results-In general, the standard of necropsy reporting was reasonably high. Tissue was retained for histopathology in $25 \%$ of necropsies and $72 \%$ of these necropsy reports included a histopathology report. Using the guidelines, the assessors judged that histopathology might have been valuable in a further $19 \%$. It was felt that routine histopathology would not have been helpful in determining the cause of death in the remaining $56 \%$. The importance of the pathologist's clinical judgement in individual cases was stressed. At reaudit, nearly two years later, there was no significant change in practice, reflecting the lack of consensus. Conclusions-Even when histopathology might contribute to finding the cause of death, it was not always done. However, the assumption that histology is invariably helpful in determining the cause of death is challenged.

(F Clin Pathol 1997;50:695-698)

Keywords: necropsy; histopathology; guidelines

The report of the national confidential inquiry into postoperative deaths (NCEPOD) of 1993, which examined records of patients who had died postoperatively, had various criticisms of the necropsy reports, including the fact that histology reports were available in only $15 \%{ }^{1}$ The guidelines for necropsy reporting produced by the Royal College of Pathologists in 1993, emphasised that " $A$ single standard should be applicable to all post mortem examinations, whether funded by the National Health Service, Coroner or Procurator Fiscal. The major difference between these types is in the frequency of histological examination. Recent publications indicate the desirability of retention of tissues for histological examination in most cases." ${ }^{2}$ The use of histopathology is debatable, however, and it has been suggested that, with limited resources, pathologists should aim to get the maximum amount of information in the most cost-effective manner. ${ }^{3}$ In the USA, some institutions routinely sample a standardised selection of tissues from every necropsy, but the College of American Pathologists recognises that there is a wide range of options, and the decision to retain tissue for histology depends on the experience of the pathologist, the objectives of the necropsy, the practice of the institution, and the likelihood of future use of the tissues. ${ }^{4}$

When the pathologists of East Anglia convened to discuss standards for necropsy reporting in 1993, they did not agree that routine histology was necessary, pointing out that with many deaths the diagnosis would not be aided by histological examination-indeed it would sometimes be difficult to know which tissues to sample. There was also discussion about the value of retaining tissue blocks, as opposed to routine sectioning and reporting of tissue samples. It was agreed that an evaluation of current practice would be valuable.

\section{Methods}

The methodology of the necropsy audit has been described elsewhere. ${ }^{5}$ It involved 32 consultant histopathologists working in the Anglia Region. Standards were agreed for the content of the report, though not for the use of histopathology. Provisional guidelines for histopathology were drawn up after consultation with several histopathologists, and taking into account published reports. ${ }^{6}$ These guidelines were less demanding, but more specific than those of the Royal College of Pathologists and are listed below.

PROVISIONAL GUIDELINES FOR THE USE OF POSTMORTEM HISTOPATHOLOGY AND/OR RETENTION OF ORGANS OR TISSUE

For immediate clinical diagnosis

1 Any organ/tissue with an abnormality macroscopically, which would be clarified by histopathology, including:

-Any tumour, whether or not contributing to death, unless adequately biopsied during life, and diagnosis made.

-Consolidation of lung: whether oedema or infection, if either was given as the cause of death in part $1 .^{6}$

2 Any organ/tissue which was thought to be abnormal during life, because of either history, clinical findings or investigations, even/especially if the organ appears normal at necropsy, including:

-Liver, if there is a recent history of unexplained liver disease; 
Table 1 Comparison of histopathology in 76 hospital and 340 coroners' necropsies

\begin{tabular}{llc}
\hline & Hospital & Coroner \\
\hline $\begin{array}{l}\text { Tissues actually retained (\% of total) } \\
\begin{array}{l}\text { Extra tissues should have been retained (\% of } \\
\text { total) }\end{array}\end{array}$ & $30(39 \%)$ & $71(21 \%)$ \\
$\begin{array}{l}\text { Total where histology advisable (\% of total) } \\
\begin{array}{l}\text { Tissues correctly retained (\% of those considered } \\
\text { to require histology) }\end{array}\end{array}$ & $21(27 \%)$ & $58(17 \%)$ \\
$\begin{array}{l}\text { Report available (\% of cases where tissues } \\
\text { retained) }\end{array}$ & $30(59 \%)$ & $129(38 \%)$ \\
\hline
\end{tabular}

-Kidney, if there was significant unexplained renal failure;

-Heart, where cause of heart failure is obscure;

-Brain, in dementia of unknown origin, etc: fix intact and refer for neuropathology.

3 Any unexpected or unexplained necropsy finding.

4 Any organ/tissue possibly affected by industrial or other pollutant, including: -pneumoconiosis, asbestosis, etc

5 Any recent operation site relevant to the cause and time of death.

6 When the cause of death remains obscure after macroscopic necropsy examination, especially in younger patients, a wide range of tissues should be examined histologically.

For future reference, multiple tissue samples

1 In any unusual or possibly genetically determined disease, for future identification of cause, or matching of tissue with other family members.

2 For tissue bank for research or teaching purposes, where appropriate permission has been obtained.

Histopathology was not thought to be particularly helpful in determining the cause of death when it appeared to be due to:

-Acute trauma, including hanging;

-Poisoning, apart from delayed death due to organ failure;

-Some cases of intraoperative death, for example ruptured aneurysm;

- Cerebrovascular accident, subarachnoid or subdural haemorrhage, except for dating of events;

-Pulmonary embolus, where there was no obvious cause or other pathology; -Myocardial ischaemia/coronary artery disease (except to date events).

These guidelines were discussed with the Anglian regional specialty committee for histopathology and cytopathology. Various individual comments were made, including doubt as to whether histology of all tumours was necessary when the gross appearances were diagnostic; and also whether it was necessary to distinguish between pulmonary oedema and bronchial pneumonia. The need for neuropathological examination of the brain in dementia of unknown origin in the elderly was queried. There was discussion about the value of routine histology in myocardial ischaemia, some pathologists believing that it would confirm an occasional diagnosis of myocarditis. These quoted views were from individuals, and were not the consensus opinion of the group.
There was no disagreement with the rest of the proposed guidelines.

An unselected sample of 15 necropsy reports from each consultant was assessed by one of two pathologists (MJG, GAG) and the use of histopathology was determined. They also assessed whether, according to the above guidelines, histopathology would be indicated. The presence of a histology report was noted. A further sample of five reports for each consultant was reaudited after nearly two years, and follow up was $94 \%$ complete.

\section{Results}

Tissue was retained in $112(25 \%)$ of the 448 reports audited. In $81(72 \%)$ of these cases ( $18 \%$ overall), the tissues had been sectioned and examined, and the report was available to the assessors. Individual pathologists varied in their practice, the number of cases where tissue had been retained and examined ranging from 0 to 12 , out of the 15 cases examined.

A further 85 reports $(19 \%)$ were identified where under the above guidelines the use of histology might have been beneficial. Overall, therefore, the assessors judged that histology might have contributed to the diagnosis in 197 cases $(44 \%)$.

Coroners' necropsies comprised 340 (76\%) of the total, and 76 necropsies (17\%) were done for the hospital. (In 32 (7\%), this was not stated.) Table 1 shows that where the guidelines indicated it would have been beneficial, histology was actually carried out in 30 (59\%) of the hospital cases, and in $71(55 \%)$ of coroners' necropsies. In coroners' cases, the necropsy report was more likely to include a histology report.

At reaudit, nearly two years later, there had been no significant change in practice. On this occasion, $25 \%$ of reports indicated tissue had been retained, and the assessors judged that a further $21 \%$ might have benefited. Where tissue had been retained, the number with reports available had fallen from $72 \%$ to $64 \%$.

\section{Discussion}

This investigation provides information about the use of histopathology in necropsy reporting in the Anglia Region (26 histopathologists were working in district general hospitals, six in the teaching hospital). Their current practice is challenged by the statement of the Royal College of Pathologists that most necropsies should include histology, and the criticism of NCEPOD that only $15 \%$ of postoperative deaths included a histopathology report. ${ }^{12}$ In Anglia, 25\% of routine necropsy reports indicated that tissue had been retained and $72 \%$ of these had a histology report attached This was in the context of an audit which showed a reasonably good standard of care and reporting: for example, $95 \%$ of reports included a comment on the brain and in $90 \%$ there was a conclusion or summary which encompassed the clinical and pathological findings. ${ }^{5}$ There was no evidence that the general standard of reporting was lower in coroners' necropsies, ${ }^{5}$ and the study did not confirm the College's concern that histopathol- 
ogy was more likely to be neglected in coroners' than in hospital necropsies. The assessors judged that $54 \%$ of necropsy examinations were unlikely to have benefited from histology. This is similar to the findings of Reid, who stated that according to clinical and gross necropsy findings, no clinically important abnormalities would have been anticipated in $46 \%$ of the tissue samples taken in 160 necropsies. ${ }^{7}$

There are clear guidelines in the Human Tissues Act for necropsies carried out at the request of a coroner, only permitting retention of tissues where they are required to confirm or elucidate the cause of death, unless permission of a close relative is obtained ${ }^{8}$ It is recognised by pathologists that the coroner is concerned with the exclusion of unnatural death, rather than precise diagnosis.

On the other hand, the College's guidelines are perhaps a council of perfection. While suggesting retention of tissues for histological examination in most cases, they do not comment on the value or use of postmortem histology, nor do they require that a report should be present-merely that the necropsy report should "indicate whether material has been taken for histology". They express anxiety that standards may fall when necropsies are undertaken for the coroner or procurator fiscal. It was, however, the opinion of pathologists in this small study that, when the examination could not be expected to contribute to the final diagnosis, omission of histopathology did not constitute a lowering of standards. As evidence, the Royal College of Pathologists guidelines refer to "recent publications", but do not give references to these.

The Anglia guidelines were an attempt to improve diagnostic yield for clinical purposes and for the Office of Population, Censuses and Surveys (now the Office for National Statistics), while accepting that pathologists should not undertake work which was unlikely to have diagnostic or other value. It should not be forgotten that all investigations have a cost, in both time and materials, and a judgement of clinical effectiveness and cost-effectiveness is essential when prioritising workload. While they were formulated to try to increase the positive information gained by histopathology, they do not take into account the potential value of negative information in excluding a diagnosis. It was emphasised that the pathologists' clinical judgement was paramount in selecting cases where histology would be of value. It is of interest that at reaudit, practice with regard to histopathology had not changed, though there was overall improvement in other aspects of necropsy reporting where agreement about standards had been reached.

The area of greatest disagreement was over the value of histology in deaths thought to be due to myocardial ischaemia or coronary artery disease. It would be useful to investigate this prospectively, to determine how often additional valuable information was obtained. Reid found only two cases of acute myocardial infarction histologically, out of 52 hearts thought macroscopically to be either normal or scarred. ${ }^{\top}$ There was also discussion about the value of histology in lung consolidation, and whether it was possible (or indeed necessary) to distinguish between oedema and infection macroscopically. Hunt found considerable discrepancy between naked eye and microscopic examination. ${ }^{6}$ Similarly, Reid found nine cases of bronchopneumonia in 44 cases where the lung was thought either normal, congested, or oedematous. $^{7}$

Postmortem histology has a low priority in any department's workload, and also has significant cost implications. Coroners are unlikely to wish to fund it, if it is not going to alter the given cause of death, and Trusts will be increasingly unwilling to fund a service which is not relevant to patient care. Necropsies make a contribution to undergraduate and postgraduate teaching, audit, research, and epidemiology': some financial recognition of the extra need for histopathology may be required.

Some pathologists indicated that they routinely took blocks of tissue, and stored them for a variable time, in case subsequent queries were made. While this may be important for risk management, there are logistic problems in storing the retained tissue. Guidelines on the amount and type of tissue, and on the length of storage would be helpful. Archival postmortem tissues have been of great value to research in the past. ${ }^{10}$ The advent of new techniques, including polymerase chain reaction, makes it possible to revisit archival material and gain new information. In any unusual or possibly genetically determined disease, retention of tissue for future identification of cause, or matching of tissue with other family members, may be valuable.

Some academics regret the loss of access to human tissue ${ }^{10}{ }^{11}$; however, the value of routine retention of apparently normal tissue outside the teaching centres is unclear. This area would merit further investigation and discussion.

\section{CONCLUSION}

This survey has shown that the Royal College of Pathologist's guidelines for histopathology after necropsy are not observed in practice, and also that the amount of tissue examined may be less than desirable, as judged by locally formulated guidelines. In this context, practice in coroners' and hospital necropsies was similar. It is suggested that the College guidelines should be reconsidered, and that there should be further discussion within the profession.

We gratefully acknowledge the agreement of the coroners in allowing their reports to be assessed in this survey. In each hospital, thanks are due to the consultant pathologists who participital, thanks are due to the consultant pathologists who particitators for help in data collection. The following hospitals participated: Addenbrooke's Hospital, Cambridge; Bedford Hospital; Hinchingbrooke Hospital, Huntingdon; Ipswich Hospital; James Paget Hospital, Great Yarmouth; Norfolk and Norwich Hospital; Papworth Hospital; Peterborough Hospital; Queen Elizabeth Hospital, King's Lynn; West Suffolk Hospital, Bury St Edmunds.

1 Royal College of Surgeons of London. National confidential enquiry into post-operative deaths (NCEPOD). London:

2 Royal College of Pathologists. Guidelines for post mortem reports. London: RCPath, 1993.

Start RD, Cross SS. Practical guidelines for necropsy: time for action. F Clin Pathol 1996;49:867-8. 
4 Hutchins GM and the Autopsy Committee of the College of American Pathologists. Practice guidelines for autopsy pathology: autopsy performance. Arch Pathol Lab Med 1994;118:19-25.

5 Williams JO, Goddard MJ, Gresham GA, Wyatt BA. Audit of necropsy reporting in East Anglia. $\mathcal{F}$ Clin Pathol 1997;50: of necrops
$691-4$.

6 Hunt CR, Benbow EW, Knox WP, McMahon RFT, McWilliam LJ. Can histopathologists diagnose bronchopMcWilliam LJ. Can histopathologists diagnose bronchop-

7 Reid WA. Cost effectiveness of routine post-mortem histology. I Clin Pathol 1987;40:459-61.
8 Timperley WR. Retention of post-mortem material. Bull $R$ Coll Pathol 1990;72:19.

9 O'Sullivan JP. The coroner's necropsy in sudden death: an under-used source of epidemiological information. $7 \mathrm{Clin}$ Pathol 1996;49:737-40.

10 Kleiner DE, Emmert-Buck MR, Liotta LA. Necropsy as a research method in the age of molecular pathology. Lancet 1995;246:945-8.

11 Harris A, Ismail I, Dilly S, Maxwell JD. Physicians' attitudes to the autopsy. $\mathcal{F} R$ Coll Physicians Lond 1993;27: 116-18. 